\title{
Improving the geometric topology of geothermal heat exchangers in oil bore-holes
}

\author{
Mykhailo Fyk ${ }^{1 *}$, Volodymyr Biletskyi ${ }^{1}$, Ihor Ryshchenko ${ }^{1}$, and Mohammed Abbood ${ }^{1}$ \\ ${ }^{1}$ National Technical University "Kharkiv Polytechnic Institute", Institute of Chemical Technology \\ and Engineering, 2 Kyrpychova St., 61002 Kharkiv, Ukraine
}

\begin{abstract}
A review has been conducted of key trends in the development of geometric topology of geothermal heat exchangers. Authors proposed approaches to improving the designs and network structures for heattransfer media circulation in the bottom-hole space of oil-and-gas reservoirs. Four geometric topologies of geothermal heat exchangers have been analysed: I- II - rectilinear vertical smooth and finned pipelines; III - IV - a cluster in the form of a set of smooth and finned single-pipe elements, representing a figure of "squirrel wheel" or "meridian sphere" type. It is shown that the most effective technical solution, which ensures the increase in the coefficient of performance $(C O P)$ of bore-hole geothermal systems is finning the heat exchanging pipes. For the heat exchangers of I-II type, the calculated increase in COP in comparison with smooth pipes is $40 \%$, and for III - IV type - $95 \%$. The key parameters influencing the $C O P$ of a geothermal heat exchanger are: the radius of fluids draining out during the heat exchange process, the radius of pipelines with circulating heat-transfer medium, the diameter of a cluster heat exchanger, the heat exchange area, the parameters of rocks thermal resistance in the bottom-hole zone of heat-receiving.
\end{abstract}

\section{Introduction}

The density of geothermal heat flux near the Earth's surface on the mainland land-based area is at an average $58 \mathrm{~mW} / \mathrm{m}^{2}$ [1]. During a detailed survey with the use of geophysical instruments in the bore-holes of the Dnipro-Donetsk depression on the territory of Ukraine, it has been specified that at depths of up to $3-4 \mathrm{~km}$ the heat fluxes have a slightly lower potential of heat power of $30-40 \mathrm{~mW} / \mathrm{m}^{2}$ [2]. At the same time, the assessment of the heat influx from heated underground rocks in works [1-2] was made by the conductive component of laminar conditionally steady-state thermodynamic processes. The convection and radiation components in the bottom-hole area were not taken into account due to the complexity of the geological structure of the rock massif at depths reached by the borehole. At the same time, according to [3-4], their fraction in the total geothermal heat flux may be greater by several orders of magnitude. This is facilitated by the conditions of free vertical fluids movement in the zone of increased natural or artificial fracturing, cavern porosity, lithological heterogeneity of the rock massif.

\footnotetext{
*Corresponding author: mfyk@ukr.net
} 
It has been obtained a sufficient amount of convincing practical evidence of the level of a specific by area geothermal heat influx from the boundary of the oil and gas reservoirs impermeable beds to the impermeable reservoir, as well as to the built in (into this reservoir) pipe-like heat exchanger $5-10 \mathrm{~W} / \mathrm{m}^{2}[5,7,9,11]$. To further increase the production of geothermal energy resources, it is necessary to improve geothermal heat exchangers in terms of their thermal engineering parameters and overall efficiency [3 -5]. Let us analyse in more detail the practical results of modern development and implementation of improved geothermal heat exchangers, concentrating on solutions concerning the geometric topologies. The underground heat exchangers of near-surface and deep heat pumps are mainly performed in the form of linear and U-shaped or linear segments of the vertical, horizontal and inclined type, ring-shaped, spiral and network-type elements, scallops, stars, flowers, brushes, or a combination of them (Fig. 1). And this is detailed and analysed in various aspects in the works [1, 4, 6-12]. In particular, in the work [12], it is emphasized that the geometric figures topology of used geothermal heat exchangers is constantly evolving with a tendency to complication, which can be observed in Fig. 1, when considering the topology variants from the top downward.

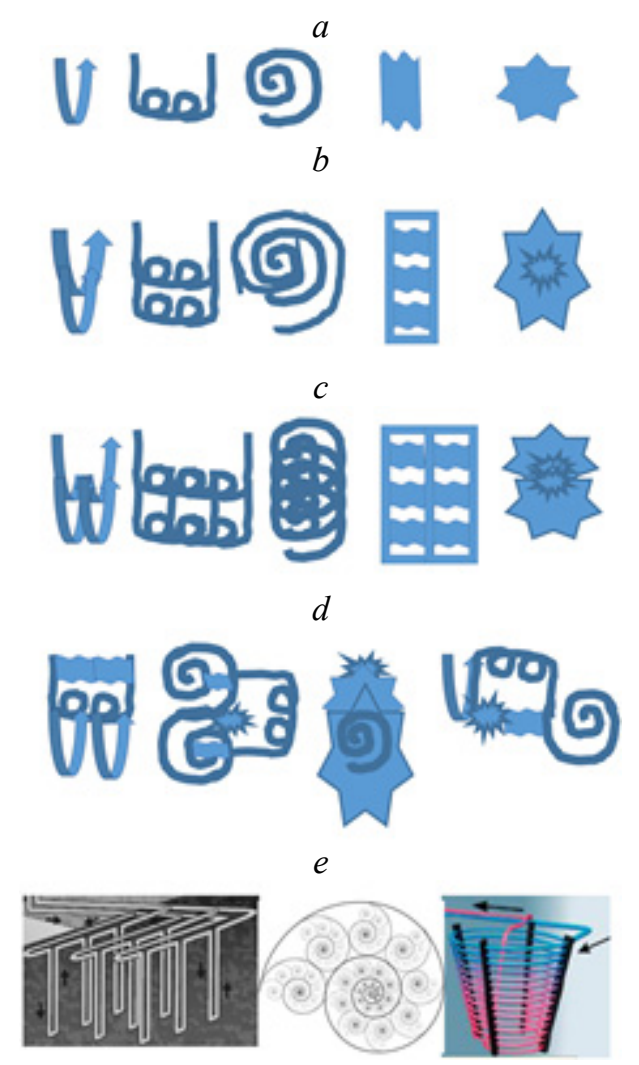

Fig. 1. The geometric topology of heat exchangers of heat pumps and geothermal systems with enclosed-type circulation through the internal heat-transfer medium. In the first row from the top, the simplest types of topologies are shown, in the bottom row - topologically more complicated: a - the basic 2D-topologies; $\mathrm{b}$ - the multi-row topology modifications; $\mathrm{c}$ - the network modifications; $\mathrm{d}$ - the combinations of multi-row and network modifications; $\mathrm{e}$ - the frequently used complicated 2D- and 3D-topologies. 
The demonstrated geometric topologies of heat exchangers can be implemented in 2Dand 3D-dimensions. In the lower part of Fig. 1, three combined geometric topologies are presented of the "basket", twisted "Tesla spiral" and "twisted spiral multi-row brush" type, which are used in geothermal heat exchange systems located in the basis of buildings, bottom river (lake), mountain and ravine geological 3D-structures [12-17]. The combinations and complications of the geometric topologies of geothermal heat exchangers provide maximum heat exchange area, improved heat influx to heat removal elements, optimal coverage of the working volume of the rock massif and, accordingly, maximum efficiency of the heat flux transfer from mine rocks to the pipe-like heat exchanger. One of the main ways to increase the heat exchange surface is finning, pimples, roughness, and the use of acicular, as well as tree-like structures [18-21].

One of the ways to improve the geometric topology is to set the intermediate geothermal heat exchangers in vertical and horizontal heat exchange sections (Fig. 2) [12]. However, the difficulties arise with the placement of internal pipe intermediate heat exchangers in the cramped conditions of bottom-hole sections of the bore-hole. To solve this problem, microfluidic systems are used, produced, in particular, by stamped way with miniature heatconducting channels. Since the total calculated diameter of intermediate heat exchangers in horizontal areas in practice does not exceed $50 \mathrm{~mm}$, then the diameters of multi-channel heat exchangers of the "pipe-in-pipe" type can be reduced to tens-hundreds of micrometres with the use of exclusively microfluidic technologies [18].

The authors of [20-21] offer their ramified geometry in order to increase the efficiency of geothermal heat exchangers, especially in the conditions of the complex structure of the rock massif. In practice, this is realized, in particular, by drain-hole drilling. In addition, artificial or natural fractures (caverns), adjacent to the wall face, play a positive role in the development of the heat exchange surface [22-23]. The heat exchange process in the bottom-hole zone can be intensified by a convection or conduction mechanism. As the working body of the heat exchange process of the bottom-hole zone can be gaseous, liquid or solid substances.

The authors [23] observed that repeated use of hydraulic fractures has a persistent effect of the influx and circulation of fluids to the bottom-hole. Otherwise, the fractures are being "grown over" with bridging agents or are taken cover with sticky pulps, closed up. The formation of additional "thermal bridges" along the thermal diffusion line of persistent heat-conducting colmated compounds, may be a promising solution (e.g., organic-silicon salts with nanopowders).

It is known that the main parameter that indicates the efficiency of a heat pump of a geothermal system, i.e., which assesses the usefulness of heat power coming to the consumer, is the COP [12-14]. However, in well-known studies there is no comparative analysis of the topologies of underground geothermal heat exchangers in terms of the COP coefficient achieved by them.

The authors of this paper think that one of the promising ways to improve underground geothermal heat exchangers is to optimize their topology by the COP criterion. To achieve this goal, the following tasks should be performed:

- analyze and classify the geometric topologies of geothermal heat exchangers of old oil and gas bore-holes, identify the main structural and topological approaches when solving the problem of increase in $C O P$ with a limited drilled out volume of the bottom-hole of a geothermal bore-hole;

- develop a mathematical model of the geothermal system "heat exchanger-rock massif", determine the key parameters influencing the COP of the geothermal heat exchanger in the bottom-hole zone of heat-receiving and assess them quantitatively. 


\section{Mathematical model. Research methods}

Accept the following nomenclature of parameters: $a$ is time of moving heat front (year); COP: Coefficient of performance; $C_{p}$ is specific heat capacity $(\mathrm{J} / \mathrm{kg} \cdot \mathrm{K}) ; D$ is pipe diameter $(\mathrm{m})$; h: convective heat transfer coefficient $\left(\mathrm{W} / \mathrm{m}^{2} \cdot \mathrm{K}\right) ; d$ is fluid drainage diameter across the reservoir $(\mathrm{m}) ; K$ is total heat transfer coefficient $\left(\mathrm{W} / \mathrm{m}^{2} \cdot \mathrm{K}\right) ; k$ is overall heat transfer coefficient in the pipe $\left(\mathrm{W} / \mathrm{m}^{2} \cdot \mathrm{K}\right) ; L$ is length $(\mathrm{m}) ; m$ is mass flow rate $(\mathrm{kg} / \mathrm{s}) ; \mathrm{Nu}$ is Nusselt number; Pr is Prandtl number; $Q$ is power-heat flow rate $(\mathrm{J} / \mathrm{s}) ; r$ is radius $(\mathrm{m}) ; R$ is linear thermal resistance coefficient $(\mathrm{K} \cdot \mathrm{m} / \mathrm{W})$; Re is Reynolds number; $S$ is cross-sectional area $\left(\mathrm{m}^{2}\right) ; t$ is time (s); $T$ is temperature $(\mathrm{K}) ; V$ is volume $\left(\mathrm{m}^{3}\right) ; v$ is flow velocity of the fluid $(\mathrm{m} / \mathrm{s}) ;$ at is thermal diffusivity $\left(\mathrm{m}^{2} / \mathrm{s}\right) ; \lambda$ is thermal conductivity $(\mathrm{W} / \mathrm{m} \cdot \mathrm{K}) ; \lambda t$ is thermal conductivity of the material of the pipe $(\mathrm{W} / \mathrm{m} \cdot \mathrm{K}) ; \rho$ is density $\left(\mathrm{kg} / \mathrm{m}^{3}\right) ; x$ is distance $(\mathrm{m})$.

The COP coefficient is determined by the ratio [12-14]:

$$
C O P=\frac{Q_{l}}{Q_{n}-Q_{l}},
$$

where $Q_{l}, Q_{n}$ is heat power, received in the heat exchanger and by the consumer, respectively.

According to the Fourier's law, it can be written for $Q_{n}$ as follows: $Q_{n}=-K\left(T_{g}-T_{w x}\right)$, where: $T_{g}, T_{w x}$ are the temperature of the mine rock at the boundary of the heat exchange zone and the temperature of the heat exchange pipeline surface, respectively, $x$ is the coordinate along the pipeline axis; $K=1 / x \cdot R$ (Fig. 2).

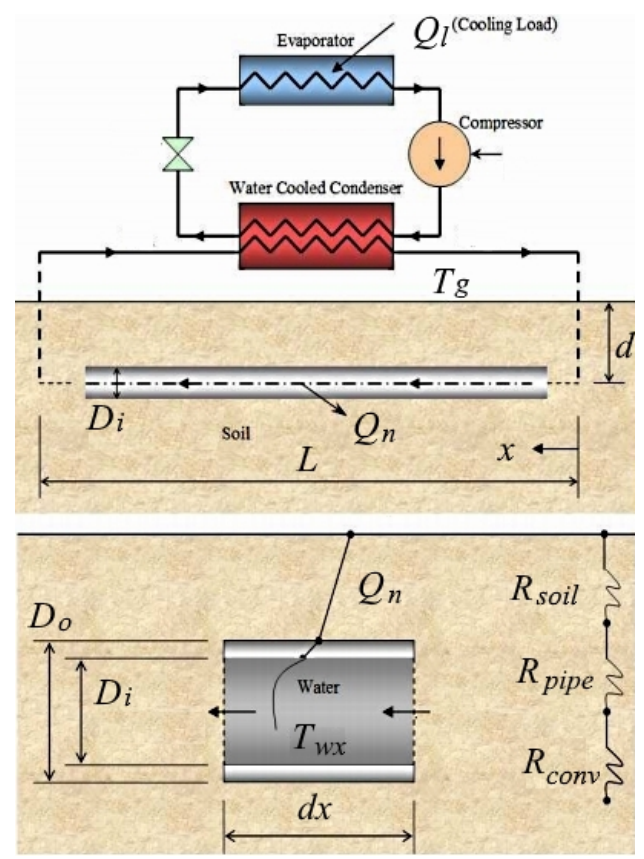

Fig. 2. The structural model of a rectilinear element of the geothermal heat exchanger (I - II type of topologies is represented).

Linear thermal resistance for the considered topological element - for single-pipe elementary rectilinear section or otherwise - total thermal resistance $R$ from the calculated boundary of the heat exchange zone volume to the axial zone of the heat transfer flux in the 
channel (pipe) of the geothermal heat exchanger, is determined with account of three transit components of the heat passage (Fig. 2) - inside the pipe $-R_{\text {conv }}$, through the wall $-R_{\text {pipe }}$, outside the pipe $-R_{\text {soil }}$ :

$$
R_{\text {total }}=R_{\text {pipe }}+R_{\text {soil }}=\frac{1}{\pi D_{i} h_{w}}+\frac{\ln \left(\frac{D_{e}}{D_{i}}\right)}{2 \pi K_{\text {pipe }}}+\frac{1}{S K_{\text {soil }}},
$$

where $D_{e}, D_{i}$ are the external and internal diameter of the heat exchange element of the pipeline; $K_{\text {pipe }}, K_{\text {soil }}$ are the heat transfer coefficient through a unit of area of a pipe and a rock massif, respectively; $h_{w}$ is the heat transfer coefficient inside the pipeline along the radius.

For the heat transfer coefficient inside the pipeline $h_{w}$, it can be written as follows: $h_{w}=2 \cdot \mathrm{Nu} \cdot k / D$, where $\mathrm{Nu}=f(\mathrm{Re}, \mathrm{Pr})$ for heat exchange pipelines is calculated by empirical formula $N u=0.023 \cdot \operatorname{Re}^{0.8} \cdot \operatorname{Pr}^{0.3}[4]$.

Thus:

$$
h_{w}=0.023 \frac{k}{D_{i}} \operatorname{Re}^{0.8} \operatorname{Pr}^{0.3}
$$

For the area $S$ of geothermal reservoir cylinder (per one meter of heat exchanger along the axial line), it can be written as follows:

$$
S=\frac{2 \pi}{\ln \left[\left(\frac{2 d}{D_{e}}\right)+\sqrt{\left(\frac{2 d}{D_{e}}\right)^{2}-1}\right]} .
$$

Using Equations $(1-4)$ for $C O P$ of pipeline with length $L$, it will be written:

$$
\begin{aligned}
& C O P=\frac{Q_{l}}{T_{w x}-T_{g}} L-Q_{l} . \\
& \frac{1}{0.023 k \pi \operatorname{Re}^{0.8} \operatorname{Pr}^{0.3}}+\frac{\ln \left(\frac{D_{e}}{D_{i}}\right)}{2 \pi K_{\text {pipe }}}+\frac{\ln \left[\left(\frac{2 d}{D_{e}}\right)+\sqrt{\left(\frac{2 d}{D_{e}}\right)^{2}-1}\right]}{2 \pi K_{\text {soil }}}
\end{aligned}
$$

The theoretical task is to increase $C O P$ with a possible decrease in the drilled out and enabled volume of rocks with convective heat transfer $\pi d^{2} L / 4$ (Fig. 2).

Consider a cluster of geothermal heat exchanger in the form of a set of single-pipe elementary rectilinear elements, analysed above. Let us assume that the cluster geometrically represents the figure of the "squirrel cage" type by external diameter $D_{t}<<d$ of $n$ elements, arranged in steps $h_{n}$, oriented vertically in height $h$ of the underground reservoir. If the height of the reservoir with convection heat exchange is $100 \mathrm{~m}$, then at $n=20$ the total length of single-pipe elementary rectilinear cluster elements $L=2000 \mathrm{~m}$.

The passing of heat flux along the height of the reservoir is determined by the thermal diffusivity parameter $A=\lambda_{o} / \rho C_{p}$, where $\lambda_{o}$ is the linear thermal conductivity coefficient from a single elementary rectilinear pipe element into the rock massif.

With decrease in the radii of the edges of the "squirrel wheel" to " 0 ", it is converted into a "meridian sphere" or "meridian ellipsoid" (Fig. 3). It can be seen from Fig. 3 that the surface of pipes 2 is increased by their finning and entering by needles 4 into the fluidpermeable stratum 5. The stratum is bounded by impermeable beds in its roof 3 and the bottom 6 . The arrows indicate the direction of the predominant inflow of the thermal energy to the bottom underneath. The direction of heat inflow from the impermeable beds 
surrounding permeable stratum depends on the local geological specifics, in particular - for negative geothermal gradients, the direction will change by 180 degrees [22 - 25].
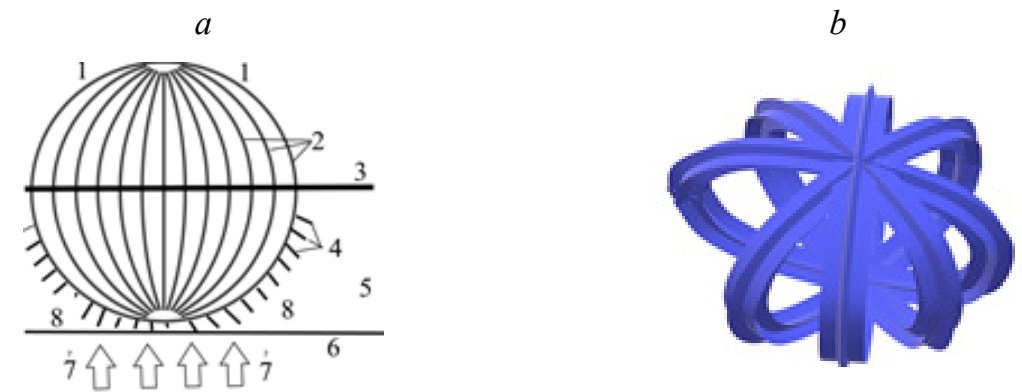

Fig. 3. The proposed geometric topology of the geothermal heat exchanger of the "meridian ellipsoid" type at the bottom-hole of the bore-hole with finning the pipe channels with heat-conducting materials (III - IV type of topologies is shown): a - the finned "meridian ellipsoid"; $b$ - the "meridian sphere" with a developed acicularity in the lower part; the arrows indicate the heat flux.

The areal thermal conductivity $K_{\text {soil }}$ for such topologies is determined as follows:

$$
K_{\text {soil }}=\frac{K_{o} \cdot K_{r} \cdot D_{e} \cdot L}{h \cdot D_{t}},
$$

where $K_{o}$ is the areal thermal conductivity of a unit pipe element of the cluster heat exchanger; $D_{e}$ is the pipe element diameter; $h$ is the height of permeable cylindrical reservoir of the fluid-permeable stratum; $K_{r}$ is the coefficient of the heat-conducting surface development of the finned cluster heat exchanger relative to a unit smooth pipe element.

Therefore, the COP for developed geometric topologies of the "squirrel wheel" or "meridian ellipsoid" type (with finning the surfaces of cluster pipe-elements) can be determined by the formula:

$$
\begin{aligned}
& C O P=\frac{Q_{l}}{T_{w x}-T_{g}} L-Q_{l} \\
& \frac{1}{0.023 k \pi \operatorname{Re}^{0.8} \operatorname{Pr}^{0.3}}+\frac{\ln \left(\frac{D_{e}}{D_{i}}\right)}{2 \pi K_{\text {pipe }}}+\frac{D_{t} h}{2 \pi K_{\text {soil }} \cdot K_{r} \cdot L \cdot D_{e}} \frac{\ln \left[\left(\frac{2 d}{D_{t}}\right)+\sqrt{\left(\frac{2 d}{D_{t}}\right)^{2}-1}\right]}{2 \pi K_{\text {soil }}}
\end{aligned}
$$

The expressions (5) and (7) are mathematical models of the "heat exchanger - rock massif" geothermal system in terms of the COP of the geothermal heat exchanger in the bottom-hole zone of heat-receiving, respectively, for: rectilinear vertical pipeline and a cluster in the form of a set of smooth and finned single-pipe elements (a figure of "squirrel wheel" or "meridian sphere" type).

\section{Results and discussion}

According to Equations (5) and (7), a comparative analysis has been made of dependences of $C O P=f\left(D, d, R_{\text {soil }}, S, D_{t}\right)$ for a rectilinear element of a geothermal heat exchanger and for the geometric topology of the "squirrel wheel" type. Herewith, the total length of heat exchange sections is assumed as equal to $L=2000 \mathrm{~m}$. The heat exchanger model was calculated in the factor space of parameters: $d=0-400 \mathrm{~m} ; D=0.1-0.14 \mathrm{~m} ; D_{t}=5-$ 
$12 \mathrm{~m} ; R_{\text {soil }}=1.35-1.40 ; S=0.67-2 \mathrm{~m}^{2}$.

In Fig. 4, the dependence of $C O P$ is represented on the radius $d$ of draining out by the bore-hole of intrastratal fluids for different diameters $D$ of pipe sections of the heat exchanger at different values of the rocks thermal resistance $R_{\text {soil }}$. For two different values of $R_{\text {soil }} / R_{o}$, differing by $5 \%$, two families of curves have been obtained $C O P=f\left(D, d, R_{\text {soil }}\right)$. A decrease in the diameter $d$ of reservoir and $D$ of the pipeline, as well as an increase in thermal resistance leads to a decrease in $C O P$. In particular, an increase in the ratio of resistances $R_{\text {soil }} / R_{o}$ by $5 \%$ at $d=400 \mathrm{~m}$ leads to decrease in COP by $40 \%$.

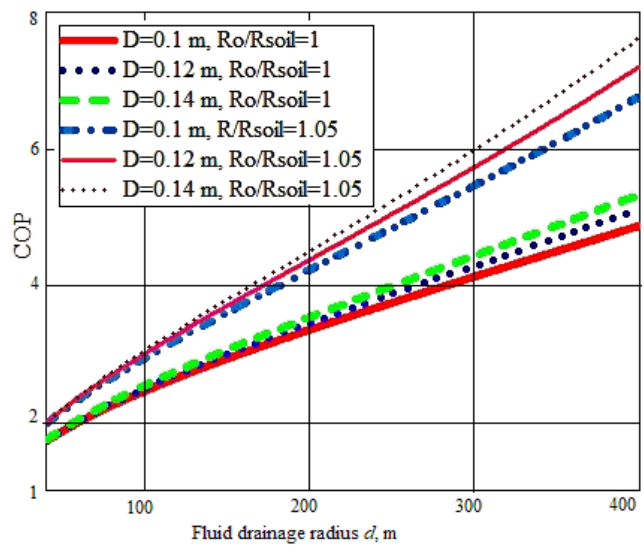

Fig. 4. Dependence of $C O P$ on the radius $d$ of draining out by the bore-hole of intrastratal fluids for different diameters $D=D_{e}$ of pipe sections of the heat exchanger and on the parameter $R_{\text {soil }} / R_{o}$.

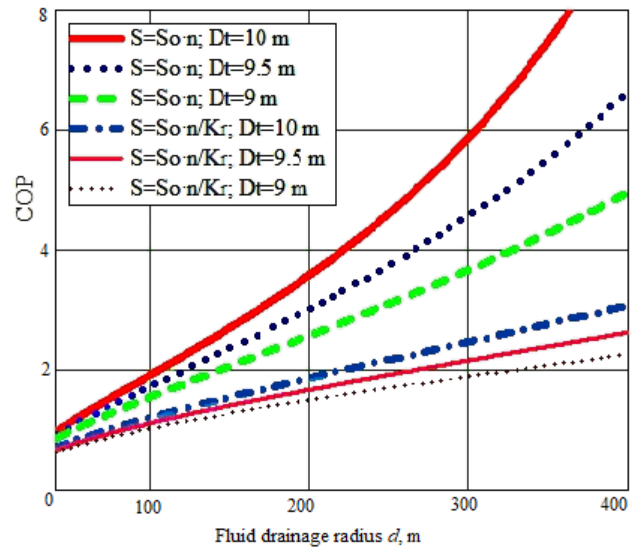

Fig. 5. Dependence of $C O P$ on the radius $d$ for different diameters of the heat exchanger $D_{t}$ at two different values of the area $S$ of heat exchange surface.

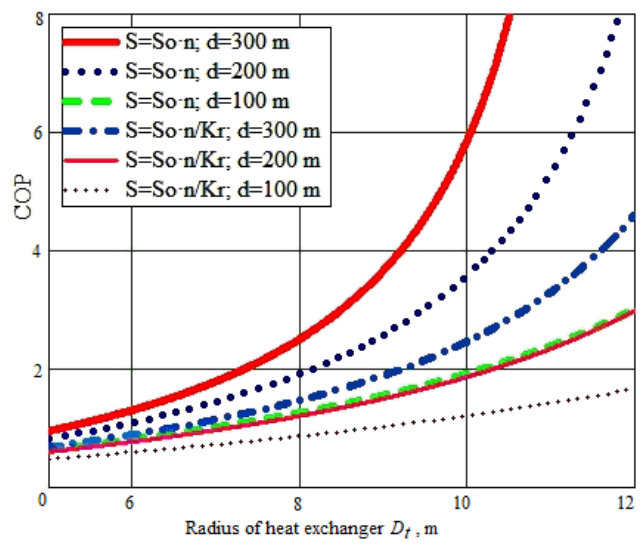

Fig. 6. Dependence of $C O P$ on the radius $D_{t}$ for different diameters $d$ at different values of the area $S$ of heat exchange surface.

In Fig. 5, the dependence of $C O P$ is represented on the radius $d$ for different diameters of the heat exchanger $D_{t}$ at different values of the area $S$ of heat exchange surface. For two different values of area $S$, differing by 3 times, two families of curves have been obtained $C O P=f\left(D_{t}, d, S\right)$. A decrease in the diameter $d$ of reservoir, $D_{t}$ of heat exchanger and area $S$ leads to a decrease in $C O P$. In particular, a decrease in the area $S$ of heat exchange surface from 0.67 to $2 \mathrm{~m}^{2}$ (per $1 \mathrm{~m}$ of the pipe-like heat exchanger length) at $d=400 \mathrm{~m}$ 
leads to a decrease in $C O P$ by $95 \%$. It should be noted that an increase in the area $S$ of the heat exchange surface is achieved due to the external finning of the pipes (Fig. 3).

In Fig. 6, the dependence of $C O P$ is represented on the radius $D_{t}$ for different diameters $d$ at different values of the area $S$ of heat exchange surface.

With an increase in the heat exchanger diameter $D_{t}$, the coefficient $C O P$ increases nonlinearly. Besides, with lower diameters $d$ of the reservoir and area $S$, the curve of $C O P$ $\left(D_{t}\right)$ is flattened. With an increase in these parameters, the velocity of COP growth increases. Thus, when the heat exchanger diameter $D_{t}$ of "squirrel wheel" type is $10 \mathrm{~m}$, $d=100 \mathrm{~m}$ and area $2 \mathrm{~m}^{2}$ (per $1 \mathrm{~m}$ of the pipe-like heat exchanger length), the $C O P=3$. At $D_{t}=10 \mathrm{~m}, d=200 \mathrm{~m}, S=2 \mathrm{~m}^{2}$, the $C O P=3.5$. At $D_{t}=10 \mathrm{~m}, d=300 \mathrm{~m}, S=2 \mathrm{~m}^{2}$, the $C O P=5.6$.

\section{Conclusions}

Four geometric topologies of geothermal heat exchangers have been analysed: I - II rectilinear vertical smooth and finned pipelines; III - IV - a cluster in the form of a set of smooth and finned single-pipe elements, representing a figure of "squirrel wheel" or "meridian sphere" type. The I-II types are applicable in cases of extensive vertical tectonic disturbances with active vertical convection heat exchange. The III-IV types are applicable in more frequent cases of horizontal extension of fluid-permeable mine rock strata (water-gas-oil-saturated). The most effective technical solution to increase the COP of bore-hole geothermal systems is finning the heat exchanging tubes. For the heat exchangers of I - II type, the calculated increase in COP in comparison with smooth pipes is $40 \%$, and for III - IV type $-95 \%$.

A mathematical model has been developed of the "heat exchanger-rock massif" geothermal system by the $C O P$ of the geothermal heat exchanger in the bottom-hole zone of heat-receiving. It has been established that the key parameters influencing the $C O P$ of a geothermal heat exchanger are: the radius of fluids draining out during the heat exchange process, the radius of pipelines with circulating heat-transfer medium, the diameter of a cluster heat exchanger, the heat exchange area, the parameters of rocks thermal resistance in the bottom-hole zone of heat-receiving. A quantitative assessment of these parameters influence on $C O P$ is given.

It should be noted the finning factor influence (acicularity, texture, roughness) of the heat exchanger surface on the mine rock thermal resistance in the inter-finned space. In subsequent studies, it is advisable to consider the influence on $C O P$ of spatial intrusion into the geometric topology of intermediate heat exchangers, profiling the heat-conducting elements of intrusion into the rock (fins, needles, tapes, pimples), the parameters of the intrusion elements network (density and network step) and nanostructured coatings of the heat-exchange surface.

The authors express their gratitude to their colleagues from the University of Otto von Guericke University Magdeburg (Germany), prof. Stefan Palis, Soren Hirsch and Dr. Alex Aman for valuable advice and comprehensive assistance in the preparation of this scientific work.

\section{References}

1. Manzella, A. (2017). Geothermal energy. EPJ Web of Conferences, (148), 00012. https://oi.org/10.1051/epjconf/201714800012

2. Limberger, J., Boxem, T., Pluymaekers, M., Bruhn, D., Manzella, A., Calcagno, P., \& van Wees, J.-D. (2018). Geothermal energy in deep aquifers: A global assessment of the resource base for direct heat utilization. Renewable and Sustainable Energy Reviews, (82), 961-975. 
https://doi.org/10.1016/i.rser.2017.09.084

3. Kutas R.I., \& Pashkevich, I.K. (2000). Geotermicheskaya i magnitnaya modeli zemnoy kory Donbassa (tektonicheskiy analiz sovmestno s dannymi GSZ). Geofizicheskiy Zhurnal, 22(4), 111-121.

4. Naili, N., Attar, I., Hazami, M., \& Farhat, A. (2012). Experimental Analysis of Horizontal Ground Heat Exchanger for Northern Tunisia. Journal of Electronics Cooling and Thermal Control, 02(03), 44-51. https://doi.org/10.4236/jectc.2012.23005

5. Alimonti, C., Berardi, D., Bocchetti, D., \& Soldo, E. (2016). Coupling of energy conversion systems and wellbore heat exchanger in a depleted oil well. Geothermal Energy, 4(1). https://doi.org/10.1186/s40517-016-0053-9

6. Lund, J.W., \& Boyd, T.L. (2015). Direct Utilization of Geothermal Energy 2015: Worldwide Review. Proceedings World Geothermal Congress. Melbourne, Australia.

7. Pei, G., \& Zhang, L. (2016). Heat transfer analysis of underground U-type heat exchanger of ground source heat pump system. SpringerPlus, 5(1). https://doi.org/10.1186/s40064-016-3548-8

8. Lund, J.W. (2010). Direct Utilization of Geothermal Energy. Energies, 3(8), 1443-1471. https://doi.org/10.3390/en3081443

9. Macenić, M., Kurevija, T., \& Strpić, K. (2018). Systematic review of research and utilization of shallow geothermal energy in Croatia. Rudarsko-Geološko-Naftni Zbornik, 33(5), 37-46. https://doi.org/10.17794/rgn.2018.5.4

10. Franco, A., \& Vaccaro, M. (2017). Recent trends in the development of heat exchangers for geothermal systems. Journal of Physics: Conference Series, 923, 012044. https://doi.org/10.1088/1742-6596/923/1/012044

11. Man, Y., Yang, H., Qu, Y., \& Fang, Z. (2015). Feasibility Investigation of the Low Energy Consumption Cooling Mode with Ground Heat Exchanger and Terminal Radiator. Procedia Engineering, 121, 423-429. https://doi.org/10.1016/i.proeng.2015.08.1088

12. Fyk, M., Fyk, I., Biletsky, V., Oliynyk, M., Kovalchuk, Y., Hnieushev, V., \& Shapchenko, Y. (2018). Theoretical and applied aspects of using a thermal pump effect in gas pipeline systems. Eastern-European Journal of Enterprise Technologies, 1(8(91)), 39-48. https://doi.org/10.15587/1729-4061.2018.121667

13. Bonamente, E., Aquino, A., \& Cotana, F. (2016). A PCM Thermal Storage for Ground-source Heat Pumps: Simulating the System Performance via CFD Approach. Energy Procedia, 101, 1079-1086. https://doi.org/10.1016/j.egypro.2016.11.147

14. Al-Hadhrami, L.M., Maslehuddin, M., \& Ali, M.R. (2016). Chemical Resistance and Mechanical Properties of Glass Fiber-Reinforced Plastic Pipes for Oil, Gas, and Power-Plant Applications. Journal of Composites for Construction, 20(1), 04015031. https://doi.org/10.1061/(asce)cc.19435614.0000592

15. Xian, G., \& Wang, Z. (2018). 2.17 Carbon Fiber Reinforced Plastics - Properties. Comprehensive Composite Materials II, 342-359. https://doi.org/10.1016/b978-0-12-803581-8.09246-8

16. Fyk, M., Palis, S., \& Kovalchuk, Yu. (2016). Gas well production enhancement on the application of innovative structural and thermal insulation nano-coatings. Visnyk of V.N. Karazin Kharkiv national university, (45), 80-85.

17. Fyk, M., Biletskyi, V., \& Abbud, M. (2018). Resource evaluation of geothermal power plant under the conditions of carboniferous deposits usage in the Dnipro-Donetsk depression. E3S Web of Conferences, (60), 00006. https://doi.org/10.1051/e3sconf/20186000006

18. Bošnjaković, M., Čikić, A., Muhič, S., \& Stojkov, M. (2017). Development of a new type of finned heat exchanger. Tehnicki Vjesnik - Technical Gazette, 24(6), 1785-1796. https://doi.org/10.17559/TV-20171011071711

19. Wang, Q., Chen, G., Chen, Q., \& Zeng, M. (2010). Review of Improvements on Shell-and-Tube Heat Exchangers With Helical Baffles. Heat Transfer Engineering, 31(10), 836-853. https://doi.org/10.1080/01457630903547602

20. Alkam, M.K., \& Al-Nimr, M.A. (1999). Improving the performance of double-pipe heat exchangers by using porous substrates. International Journal of Heat and Mass Transfer, 42(19), 
3609-3618. https://doi.org/10.1016/s0017-9310(99)00033-2

21. Nickolas, N., Moorthy, P., Oumer, A. N., \& Ishak, M. (2017). A review on improving thermalhydraulic performance of fin-and-tube heat exchangers. IOP Conference Series: Materials Science and Engineering, (257), 012049. https://doi.org/10.1088/1757-899x/257/1/012049

22. Olasolo, P., Juárez, M.C., Morales, M.P., D'Amico, S., \& Liarte, I.A. (2016). Enhanced geothermal systems (EGS): A review. Renewable and Sustainable Energy Reviews, (56), 133 144. https://doi.org/10.1016/j.rser.2015.11.031

23. Zimmermann, G., Tischner, T., Legarth, B., \& Huenges, E. (2009). Pressure-dependent Production Efficiency of an Enhanced Geothermal System (EGS): Stimulation Results and Implications for Hydraulic Fracture Treatments. Pure and Applied Geophysics, 166(5-7), 10891106. https://doi.org/10.1007/s00024-009-0482-5

24. Polishchuk, S., Falko, V., Polishchuk, A., \& Demydenko, A. (2019). Assurance of guaranteed atmosphere air quality for a point emission source. Mining of Mineral Deposits, 13(2), 103-110. https://doi.org/10.33271/mining13.02.103

25. Jung, Y.-J., Kim, H.-J., Choi, B.-E., Jo, J.-H., \& Cho, Y.-H. (2016). A Study on the Efficiency Improvement of Multi-Geothermal Heat Pump Systems in Korea Using Coefficient of Performance. Energies, 9(5), 356. https://doi.org/10.3390/en9050356 